\title{
A stratified model for health outcomes in ankylosing spondylitis
}

\author{
Pedro Machado, ${ }^{1,2}$ Robert Landewé, ${ }^{3}$ Jürgen Braun, ${ }^{4}$ Kay-Geert A Hermann, ${ }^{5}$ \\ Xenofon Baraliakos, ${ }^{4}$ Daniel Baker, ${ }^{6}$ Ben Hsu, ${ }^{6}$ Désirée van der Heijde ${ }^{2}$
}

'Department of Rheumatology,

Coimbra University Hospital,

Coimbra, Portugal

2Department of Rheumatology, Leiden University Medical

Center, Leiden, The Netherlands

${ }^{3}$ Department of Rheumatology,

Academic Medical Center/

Amsterdam University,

Amsterdam and Atrium

Medical Center, Heerlen,

The Netherlands

${ }^{4}$ Department of Rheumatology,

Rheumazentrum Ruhrgebiet

Herne, Ruhr-University

Bochum, Germany

${ }^{5}$ Department of Radiology,

Charité Medical School,

Berlin, Germany

${ }^{6}$ Research and Development,

Centocor Inc, Malvern

Pennsylvania, USA

\section{Correspondence to}

Professor Désirée van

der Heijde, Department

of Rheumatology, Leiden

University Medical Center,

P O Box 9600, 2300 RC Leiden,

The Netherlands;

d.vanderheijde@kpnplanet.nl

Accepted 11 June 2011

\begin{abstract}
Objective To investigate the relationships between several health outcomes in ankylosing spondylitis (AS).

Methods Baseline pretreatment data from 214 patients with AS participating in the AS Study for the Evaluation of Recombinant Infliximab Therapy were analysed. Measures of health-related quality of life (HROOL) and physical function were used as dependent variables in linear regression analysis. Associations between HROoL (36-Item Short Form (SF-36)), physical function, clinical disease activity, spinal mobility, structural damage, MRI inflammation, disease duration, age, gender, body mass index and HLA-B27 were explored. Univariate associations were retested in multivariate models. The robustness of the models was evaluated by sensitivity analyses.
\end{abstract}

Results The physical component of SF-36 was independently associated with measures of physical function and disease activity (adjusted $R^{2}\left(\operatorname{adj} R^{2}\right)=$ 0.39-0.40). The mental component of SF-36 was independently associated with physical function $\left(\operatorname{adj} R^{2}=0.07\right)$. Physical function was independently associated with measures of spinal mobility and disease activity (adj $\left.R^{2}=0.39-0.45\right)$. Spinal mobility was hierarchically shown to be an intermediate variable between structural damage and physical function, while physical function was shown to be intermediate between spinal mobility and the physical component of SF-36.

Conclusion According to the proposed stratified model for health outcomes in AS, HROOL is determined by physical function and disease activity, physical function is determined by spinal mobility and disease activity, and spinal mobility is determined by structural damage and inflammation of the spine. As more is learnt about how to measure AS, knowledge about the disease improves and better decisions can be made on the assessment and treatment of this disease.

\section{INTRODUCTION}

Health outcomes include different aspects of health and illness and their consequences on a person's life. These include health status (symptom severity and degree of functional limitation), impairment (alteration of normal body structure or biofunction), quality of life (subjective appraisal of health status), costs (monetary costs of obtaining care and costs of lost work productivity) and mortality. ${ }^{1}$

The Assessment of SpondyloArthritis international Society (ASAS) has recommended a core set of validated ankylosing spondylitis (AS) measures of impairment and health status to be used in clinical trials and clinical practice..$^{2-4}$ Measurement instruments for radiographic damage $e^{6}$ and for MRI inflammation ${ }^{7}$ have also been developed and, recently, a new index for measuring disease activity-the AS Disease Activity Score (ASDAS)was proposed and validated in AS. ${ }^{9-11}$

The spectrum of AS is heterogeneous and the relationships between health outcomes are complex and incompletely understood. Presumably, there is a generic hierarchical order of domains, with health-related quality of life (HRQoL) at the top and signs and symptoms (and MRI inflammation) at the bottom. HRQoL can be thought of as the highest multidimensional goal dependent on other domains (eg, health status and impairment), reflecting the overall impact of the illness (including signs and symptoms) and its treatment on patients and their response to these impacts. However, we do not know exactly how these domains interrelate. Improved understanding about these relationships will deepen our knowledge of AS and its management, treatment and impact on patients and society.

This theoretical concept is not new to rheumatic diseases (or to most chronic diseases), and goes back to the writings of Tennant ${ }^{12}$ and Fries ${ }^{13}$ and to what was to become the International Classification of Impairments, Disabilities, and Handicaps of the World Health Organization. In this schema, as described by Tennant, ${ }^{12}$ disease gives rise to impairment, defined as 'any loss or abnormality of psychological, physiological, or anatomical structure or function'; impairment itself may lead to disability, defined as 'any restriction or lack of ability to perform an activity in the manner or within the range considered normal for a human being'; impairments and disabilities, by interacting with the physical and social environment, can result in handicap, defined as a 'disadvantage for the given individual that limits or prevents the fulfilment of a role that is normal'; and at the end of the diseasehandicap continuum we can find quality of life, a broader outcome that can be influenced by a whole series of other factors such as self-esteem, coping skills, age, gender and ethnicity. ${ }^{12}$

Despite being a conceptual frame shared between several chronic diseases, the evidence for AS is lacking as the number of previous reports analysing the relationship between outcomes is small, they included small numbers of patients and focused on a limited number of outcomes. A more broad analysis-adjusting for potential confounders and including a large number of health outcomes simultaneously - is lacking, and is of utmost importance as it may offer a more solid conceptual basis for thinking about outcomes in AS and for understanding what we are measuring when assessing patients with this disease. In particular, 
the availability of inflammation assessed on MRI of the spine in a large number of patients is a unique feature of the current dataset.

In this study we investigated the relationships between HRQoL, physical function, disease activity, spinal mobility and structural damage in detail and propose a stratified model for health outcomes in AS.

\section{METHODS}

\section{AS patient population}

This study investigated a representative baseline $80 \%$ random sample (224 patients) of the AS Study for the Evaluation of Recombinant Infliximab Therapy (ASSERT) cohort. ${ }^{14}$ Ten patients were excluded from the analysis owing to incomplete radiographic assessment $(n=7)$, incomplete MRI assessment $(n=1)$ or both $(n=2)$. The final number of patients included in this study was 214 .

In brief, ASSERT was a double-blind placebo-controlled clinical trial with infliximab that included patients with AS (according to the modified New York criteria) ${ }^{15}$ for at least 3 months prior to screening, with a Bath AS Disease Activity Index (BASDAI) $\geq 4$ (range 0-10) and a Spinal Pain Assessment Score $\geq 4$ (range 0-10 cm, visual analogue scale). Detailed inclusion and exclusion criteria of patients in the ASSERT trial have been described previously. ${ }^{14}$

\section{Measures of health outcomes}

Two patient-reported outcomes were used as measures of HRQoL and physical function: the 36-Item Short Form (SF-36) health survey questionnaire ${ }^{16}$ (both the SF-36 Physical Component Summary Score (SF-36 PCS) and the SF-36 Mental Component Summary Score (SF-36 MCS)) and the Bath AS Functional Index (BASFI). ${ }^{17}$ It should be noted that, although often mislabelled as a quality of life measure, the SF-36 is in fact a health status measure and it should be interpreted as such when we use the term HRQoL.

The BASDAI, ${ }^{18}$ the ASDAS ${ }^{9-11}$ and the level of C-reactive protein (CRP) were included as measures of clinical disease activity. Spinal mobility was assessed using the Bath AS Metrology Index (BASMI), ${ }^{19-21}$ structural damage was assessed by the modified Stoke AS Spine Score (mSASSS) ${ }^{6}$ and MRI spinal inflammation was assessed by the AS spinal MRI Activity (ASspiMRI-a) score. ${ }^{8}$ All these measurement tools have been validated and are recommended for use in AS. ${ }^{4} 22$ A more detailed description of these well-known outcome measures can be found in the online supplement.

\section{Statistical analysis}

All data are expressed as median (IOR) or proportion if applicable. Pearson (normally distributed variables) and Spearman correlation coefficients (not normally distributed variables) were used to build a correlation matrix between health outcomes.

Possible associations between BASFI, SF-36 (physical and mental component scores) and a large number of outcome measures (ASDAS, BASDAI, CRP, BASMI, mSASSS, ASspiMRI-a) and clinical-demographic variables (disease duration, age, gender, body mass index (BMI) and HLA-B27) were first explored by univariate linear regression analysis (using SF36-PCS, SF-36 MCS and BASFI as dependent variables). Variables with univariate associations with a $p$ value $<0.10$ were retested in multivariate models. By default, all multivariate models were adjusted for disease duration, age, BMI and gender.
Separate multivariate models were run using either ASDAS or BASDAI as independent variables (as they represent the same health outcome), and using either mSASSS or BASMI (to avoid collinearity and because we wanted to test if BASMI is an intermediate variable between mSASSS and BASFI). A similar approach (and for the same reasons) was used for BASMI or BASFI as the regressors.

As measures of the strength of the relationship between the models and the dependent variable, we used the R-square $\left(R^{2}\right)$ value (the coefficient of determination), which is the squared value of the multiple correlation coefficient (R) and shows how much variation in the dependent variable is explained by the model. As a further measure of the strength of the model fit, we used the adjusted R-square $\left(\operatorname{adj} R^{2}\right)$ value, which compensates for model complexity providing a fairer comparison of multivariate model performance.

Non-normally distributed variables (mSASSS, ASspiMRI-a score, CRP and disease duration) underwent a normalisation procedure based on rank order using the van der Waerden technique before being entered into the linear regression analysis. All tests were two-sided and $p$ values $<0.05$ were considered statistically significant. Analyses were performed using SPSS Version 16.

\section{RESULTS}

\section{Baseline characteristics of the study population}

Table S2 in the online supplement shows the baseline characteristics of the study population. The study population was typical of patients with moderate to severe AS, with poor physical function (median BASFI 5.7), high disease activity (median BASDAI 6.5 and median ASDAS 4.0) and substantial impairment of spinal mobility (median BASMI 4.6). The median SF-36 PCS score (29.5) was well below that of the general population of the USA and Europe (range 49.7-52.7). ${ }^{23}$ However, the median SF-36 MCS score (47.1) was in the lower range of that of the general population of the USA and Europe (range 47.6-54.0). ${ }^{23}$

\section{Correlation matrix for health outcomes}

Table 1 presents a correlation matrix for all health outcomes in our population. SF-36 MCS correlated weakly with BASFI $(\mathrm{r}=-0.28)$, BASDAI $(\mathrm{r}=-0.25)$ and ASDAS $(\mathrm{r}=-0.13)$. SF-36 PCS correlated moderately well with BASFI ( $r=-0.58)$, BASDAI $(\mathrm{r}=-0.47)$, ASDAS $(\mathrm{r}=-0.40)$ and weakly with BASMI $(\mathrm{r}=-0.20)$. BASFI correlated moderately well with BASDAI ( $r=0.45)$, ASDAS $(\mathrm{r}=0.38)$, BASMI $(\mathrm{r}=0.42)$ and weakly with mSASSS $(\mathrm{r}=0.18)$. BASMI correlated moderately well with mSASSS $(r=0.59)$ and weakly with ASspiMRI-a $(r=0.30)$.

Univariate associations between BASFI, SF-36 PCS, SF-36 MCS and other outcome measures and clinical-demographic variables Table 2 shows the results of univariate linear regression analysis using physical function and HRQoL (physical and mental components) as dependent variables:

1. BASFI was positively associated with ASDAS $\left(\mathrm{R}^{2}=0.15\right)$, BASDAI $\left(\mathrm{R}^{2}=0.20\right)$, BASMI $\left(\mathrm{R}^{2}=0.18\right), \operatorname{mSASSS}\left(\mathrm{R}^{2}=0.040\right)$, age $\left(R^{2}=0.038\right)$ and $B M I\left(R^{2}=0.064\right)$.

2. SF-36 PCS was negatively associated with BASFI $\left(\mathrm{R}^{2}=0.33\right)$, ASDAS $\left(\mathrm{R}^{2}=0.16\right)$, BASDAI $\left(\mathrm{R}^{2}=0.22\right)$, BASMI $\left(\mathrm{R}^{2}=0.038\right)$ and age $\left(R^{2}=0.037\right)$, and positively associated with male gender $\left(\mathrm{R}^{2}=0.034\right)$.

3. SF-36 MCS was negatively associated with BASFI $\left(\mathrm{R}^{2}=0.076\right)$, ASDAS $\left(\mathrm{R}^{2}=0.018\right)$, BASDAI $\left(\mathrm{R}^{2}=0.064\right)$ and $\mathrm{BMI}\left(\mathrm{R}^{2}=0.039\right)$. 
Table 1 Correlation matrix between health outcomes in ankylosing spondylitis

\begin{tabular}{|c|c|c|c|c|c|c|c|c|c|}
\hline & & SF-36 MCS & SF-36 PCS & BASFI & BASDAI & ASDAS & BASMI & mSASSS & ASspiMRI-a \\
\hline \multirow[t]{2}{*}{ SF-36 MCS } & $r$ & 1 & -0.01 & -0.28 & -0.25 & -0.13 & -0.07 & 0.04 & 0.08 \\
\hline & $\mathrm{p}$ Value & NA & 0.88 & $<0.001$ & $<0.001$ & 0.051 & 0.279 & 0.596 & 0.255 \\
\hline \multirow[t]{2}{*}{ SF-36 PCS } & r & & 1 & -0.58 & -0.47 & -0.40 & -0.20 & -0.10 & 0.13 \\
\hline & $\mathrm{p}$ Value & & NA & $<0.001$ & $<0.001$ & $<0.001$ & 0.004 & 0.154 & 0.051 \\
\hline \multirow[t]{2}{*}{ BASFI } & $r$ & & & 1 & 0.45 & 0.38 & 0.42 & 0.18 & 0.04 \\
\hline & $\mathrm{p}$ Value & & & NA & $<0.001$ & $<0.001$ & $<0.001$ & 0.008 & 0.535 \\
\hline \multirow[t]{2}{*}{ BASDAI } & r & & & & 1 & 0.68 & -0.03 & -0.13 & -0.12 \\
\hline & $\mathrm{p}$ Value & & & & NA & $<0.001$ & 0.631 & 0.064 & 0.079 \\
\hline \multirow[t]{2}{*}{ ASDAS } & $r$ & & & & & 1 & 0.11 & 0.11 & 0.14 \\
\hline & $\mathrm{p}$ Value & & & & & NA & 0.103 & 0.127 & 0.045 \\
\hline \multirow[t]{2}{*}{ BASMI } & r & & & & & & 1 & 0.59 & 0.30 \\
\hline & $\mathrm{p}$ Value & & & & & & NA & $<0.001$ & $<0.001$ \\
\hline \multirow[t]{2}{*}{ mSASSS } & r & & & & & & & 1 & 0.38 \\
\hline & $\mathrm{p}$ Value & & & & & & & NA & $<0.001$ \\
\hline \multirow[t]{2}{*}{ ASspiMRI-a } & r & & & & & & & & 1 \\
\hline & $\mathrm{p}$ Value & & & & & & & & NA \\
\hline
\end{tabular}

p Values $<0.05$ are highlighted in bold.

ASDAS, Ankylosing Spondylitis Disease Activity Score; ASspiMRI-a, Ankylosing Spondylitis spinal MRI activity; BASDAI, Bath Ankylosing Spondylitis Disease Activity Index; BASFI, Bath Ankylosing Spondylitis Functional Index; BASMI, linear definition of the Bath Ankylosing Spondylitis Metrology Index; mSASSS, modified Stoke Ankylosing Spondylitis Spine Score; SF-36 PCS, SF-36 Physical Component Summary Score; SF-36 MCS, SF-36 Mental Component Summary Score.

Table 2 Associations between BASFI, SF-36 PCS and SF-36 MCS (dependent variables) and other outcome measures and clinical-demographic variables (univariate linear regression analyses)

\begin{tabular}{|c|c|c|c|c|c|c|c|c|c|c|c|c|}
\hline & \multicolumn{4}{|l|}{ BASFI } & \multicolumn{4}{|l|}{ SF-36 PCS } & \multicolumn{4}{|l|}{ SF-36 MCS } \\
\hline & B (95\% CI) & $\beta$ & $\mathbf{R}^{2}$ & p Value & B (95\% CI) & $\beta$ & $\mathbf{R}^{2}$ & p Value & B (95\% CI) & $\beta$ & $\mathbf{R}^{2}$ & p Value \\
\hline BASFI & NA & NA & NA & NA & $\begin{array}{l}-2.198 \\
(-2.620 \text { to }-1.776)\end{array}$ & -0.576 & 0.332 & $<0.001$ & $\begin{array}{l}-1.565 \\
(-2.303 \text { to }-0.828)\end{array}$ & -0.276 & 0.076 & $<0.001$ \\
\hline ASDAS & $\begin{array}{l}0.861 \\
(0.581 \text { to } 1.141)\end{array}$ & 0.384 & 0.148 & $<0.001$ & $\begin{array}{l}-3.383 \\
(-4.445 \text { to }-2.321)\end{array}$ & -0.396 & 0.157 & $<0.001$ & $\begin{array}{l}-1.695 \\
(-3.397 \text { to } 0.007)\end{array}$ & -0.134 & 0.018 & 0.051 \\
\hline BASDAI & $\begin{array}{l}0.562 \\
(0.411 \text { to } 0.713)\end{array}$ & 0.450 & 0.203 & $<0.001$ & $\begin{array}{l}-2.249 \\
(-2.817 \text { to }-1.680)\end{array}$ & -0.472 & 0.223 & $<0.001$ & $\begin{array}{l}-1.796 \\
(-2.723 \text { to }-0.869)\end{array}$ & -0.254 & 0.064 & $<0.001$ \\
\hline CRP & $\begin{array}{l}0.194 \\
(-0.076 \text { to } 0.464)\end{array}$ & 0.097 & 0.009 & 0.158 & $\begin{array}{l}-0.857 \\
(-1.884 \text { to } 0.170)\end{array}$ & -0.112 & 0.013 & 0.101 & $\begin{array}{l}0.346 \\
(-1.188 \text { to } 1.880)\end{array}$ & 0.031 & 0.001 & 0.657 \\
\hline BASMI & $\begin{array}{l}0.518 \\
(0.368 \text { to } 0.668)\end{array}$ & 0.423 & 0.179 & $<0.001$ & $\begin{array}{l}-0.915 \\
(-1.535 \text { to }-0.295)\end{array}$ & -0.196 & 0.038 & 0.004 & $\begin{array}{l}-0.515 \\
(-1.452 \text { to } 0.421)\end{array}$ & -0.074 & 0.006 & 0.279 \\
\hline mSASSS & $\begin{array}{l}0.387 \\
(0.129 \text { to } 0.645)\end{array}$ & 0.199 & 0.040 & 0.003 & $\begin{array}{l}-0.826 \\
(-1.825 \text { to } 0.172)\end{array}$ & -0.111 & 0.012 & 0.104 & $\begin{array}{l}0.594 \\
(-0.896 \text { to } 2.084)\end{array}$ & 0.054 & 0.003 & 0.433 \\
\hline ASspiMRI-a & $\begin{array}{l}0.120 \\
(-0.153 \text { to } 0.393)\end{array}$ & 0.059 & 0.004 & 0.387 & $\begin{array}{l}0.791 \\
(-0.248 \text { to } 1.830)\end{array}$ & 0.102 & 0.011 & 0.135 & $\begin{array}{l}0.769 \\
(-0.779 \text { to } 2.317)\end{array}$ & 0.067 & 0.005 & 0.328 \\
\hline $\begin{array}{l}\text { Disease } \\
\text { duration }\end{array}$ & $\begin{array}{l}-0.043 \\
(-0.347 \text { to } 0.178)\end{array}$ & -0.084 & 0.002 & 0.528 & $\begin{array}{l}0.050 \\
(-0.953 \text { to } 1.052)\end{array}$ & 0.007 & 0.001 & 0.922 & $\begin{array}{l}0.226 \\
(-1.262 \text { to } 1.715)\end{array}$ & 0.021 & 0.000 & 0.765 \\
\hline Age & $\begin{array}{l}0.037 \\
(0.012 \text { to } 0.063)\end{array}$ & 0.196 & 0.038 & 0.004 & $\begin{array}{l}-0.140 \\
(-0.237 \text { to }-0.043)\end{array}$ & -0.192 & 0.037 & 0.005 & $\begin{array}{l}-0.106 \\
(-0.253 \text { to } 0.040)\end{array}$ & -0.098 & 0.010 & 0.152 \\
\hline $\begin{array}{l}\text { Gender } \\
\text { (male) }\end{array}$ & $\begin{array}{l}-0.343 \\
(-0.965 \text { to } 0.279)\end{array}$ & -0.074 & 0.006 & 0.279 & $\begin{array}{l}3.220 \\
(0.880 \text { to } 5.559)\end{array}$ & 0.183 & 0.034 & 0.007 & $\begin{array}{l}0.528 \\
(-3.005 \text { to } 4.061)\end{array}$ & 0.020 & 0.000 & 0.769 \\
\hline $\mathrm{BMI}$ & $\begin{array}{l}0.119 \\
(0.057 \text { to } 0.181)\end{array}$ & 0.253 & 0.064 & $<0.001$ & $\begin{array}{l}-0.191 \\
(-0.433 \text { to } 0.050)\end{array}$ & -0.107 & 0.011 & 0.120 & $\begin{array}{l}-0.527 \\
(-0.881 \text { to }-0.173)\end{array}$ & -0.198 & 0.039 & 0.004 \\
\hline HLA-B27+ & $\begin{array}{l}0.238 \\
(-0.607 \text { to } 1.083)\end{array}$ & 0.038 & 0.001 & 0.580 & $\begin{array}{l}-0.172 \\
(-3.397 \text { to } 3.053)\end{array}$ & -0.007 & 0.001 & 0.916 & $\begin{array}{l}-1.976 \\
(-6.756 \text { to } 2.805)\end{array}$ & -0.056 & 0.003 & 0.416 \\
\hline
\end{tabular}

p Values $<0.05$ are highlighted in bold.

ASDAS, Ankylosing Spondylitis Disease Activity Score; ASspiMRI-a, Ankylosing Spondylitis spinal MRI activity; B, regression coefficient; $\beta$, standardised coefficient; BASDAl, Bath Ankylosing Spondylitis Disease Activity Index; BASFI, Bath Ankylosing Spondylitis Functional Index; BASMI, linear definition of the Bath Ankylosing Spondylitis Metrology Index; BMI, Body Mass Index; CRP, C-reactive protein; mSASSS, modified Stoke Ankylosing Spondylitis Spine Score; $\mathrm{R}^{2}$, an estimate of the proportion of variance in the dependent variable accounted for by the regression; SF-36 PCS, SF-36 Physical Component Summary Score; SF-36 MCS, SF-36 Mental Component Summary Score; NA, not applicable.

\section{Multivariate linear regression analysis for BASFI, SF-36 PCS and SF-36 MCS}

Independent associations with BASFI, SF-36 PCS and SF-36 MCS were explored using multivariate linear regression analysis. By default, all models were adjusted for disease duration, age, BMI and gender. The results are presented in tables 3-5 and summarised below:

1. BASFI was independently associated with BASMI and with measures of clinical disease activity (ASDAS or BASDAI) (table 3, models 1 and 2). If BASMI and mSASSS were forced into the same model as regressors simultaneously, the mSASSS contribution did not reach statistical significance owing to collinearity (data not shown).

2. When BASMI was replaced by mSASSS in the BASFI models (table 3 , models 3 and 4), both ASDAS/BASDAI and mSASSS were independently associated with BASFI, suggesting that BASMI is hierarchically an intermediate variable between mSASSS and BASFI. This is supported by the improved fit in the model with BASFI when BASMI $\left(\operatorname{adj} R^{2}=0.39-0.45\right)$ is used instead of mSASSS 


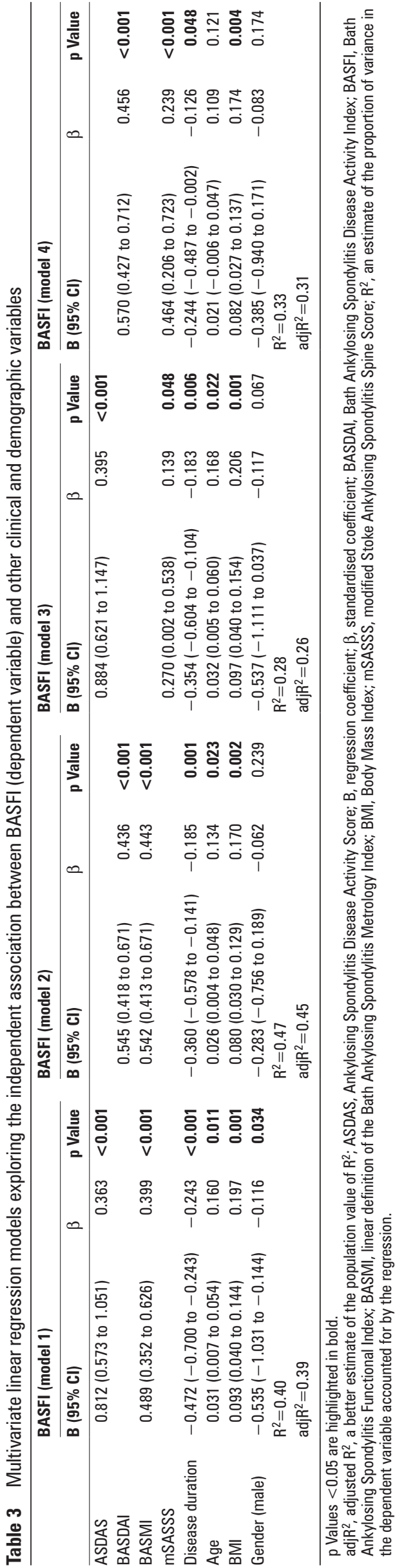

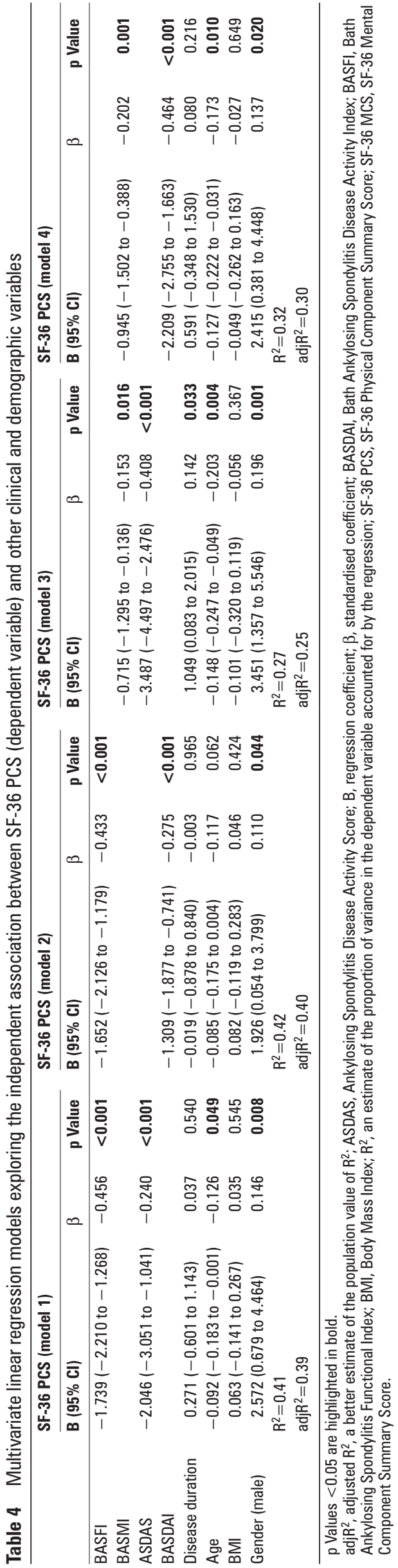


$\left(\operatorname{adj} R^{2}=0.26-0.31\right) \quad$ in otherwise similar multivariate models (table 3 ).

3. SF-36 PCS was independently determined by BASFI and by measures of clinical disease activity (ASDAS or BASDAI) (table 4, models 1 and 2). If BASFI and BASMI were forced into the same model as regressors simultaneously, the contribution of BASMI was not statistically significant (collinearity, data not shown).

4. When BASFI was replaced by BASMI in the SF-36 PCS models (table 4, models 3 and 4), both ASDAS/BASDAI and BASMI were independently associated with SF-36 PCS, suggesting that BASFI is hierarchically an intermediate variable between BASMI and SF-36 PCS. This is supported by the improved fit in the model with SF-36 PCS when BASFI $\left(\operatorname{adj} R^{2}=0.39-0.40\right)$ is used instead of BASMI $\left(\operatorname{adj} R^{2}=0.25-\right.$ 0.30 ) in otherwise similar multivariate models (table 4).

5. SF-36 MCS was independently determined by BASFI when ASDAS was used as an independent variable (ASDAS lost statistical significance in this model, table 5, model 1), and by disease activity when BASDAI was used as an independent variable (BASFI lost statistical significance in this model, table 5, model 2). When BASFI was excluded from the models, ASDAS was also independently associated with SF-36 MCS (table 5, model 3: $\mathrm{r}=-1.82, \mathrm{p}=0.035$ ), similarly to BASDAI (table 5, model 4: $\mathrm{r}=-1.74, \mathrm{p}<0.001$ ). Overall, the robustness of the models was lower for SF-36 MCS $\left(\operatorname{adj} R^{2}=0.07-0.10\right)$ compared with SF-36 PCS and BASFI models.

6. An increase of 1 unit in BASMI leads to an estimated average increase of 0.49 in BASFI independent of the effect of ASDAS; similarly, an increase of 1 unit in ASDAS leads to an increase of 0.81 in BASFI (table 3). An increase of 1 unit in BASFI leads to a decrease of 1.7 in SF-36 PCS (table 4) and to a decrease of 1.2 in SF-36 MCS (table 5), independent of the effect of ASDAS; similarly, an increase of 1 unit in ASDAS leads to a decrease of 2.0 units in SF-36 PCS (table 4).

\section{DISCUSSION}

In a large cohort of patients we have studied the relationships between health outcomes in AS. This analysis showed that physical function is independently determined both by the level of clinical disease activity and by the degree of spinal mobility impairment, and that the physical component of HRQoL is independently determined by physical function and by the level of clinical disease activity. This study also supports the view that spinal mobility is hierarchically an intermediate variable between structural damage and physical function, while physical function itself is intermediate between spinal mobility and the physical component of SF-36.

Combined with a previous analysis of the same cohort showing that spinal mobility impairment in AS is independently determined both by irreversible radiographic spinal damage and by reversible MRI spinal inflammation, ${ }^{24}$ the results from this study allow us to propose a stratified model for health outcomes in AS (figure 1). This stratified model endorses the ASAS core set choice of relevant domains, ${ }^{2-4}$ and suggests that the generic domain HRQoL is highest in hierarchy and that all other domains contribute to some extent and independently to HRQoL.

The results were largely similar using either ASDAS or BASDAI as the measurement tool for clinical disease activity, providing further evidence for the validity of the ASDAS as a new measure of disease activity in AS. Some discrepancies were observed for the SF-36 MCS models, where BASFI and BASDAI

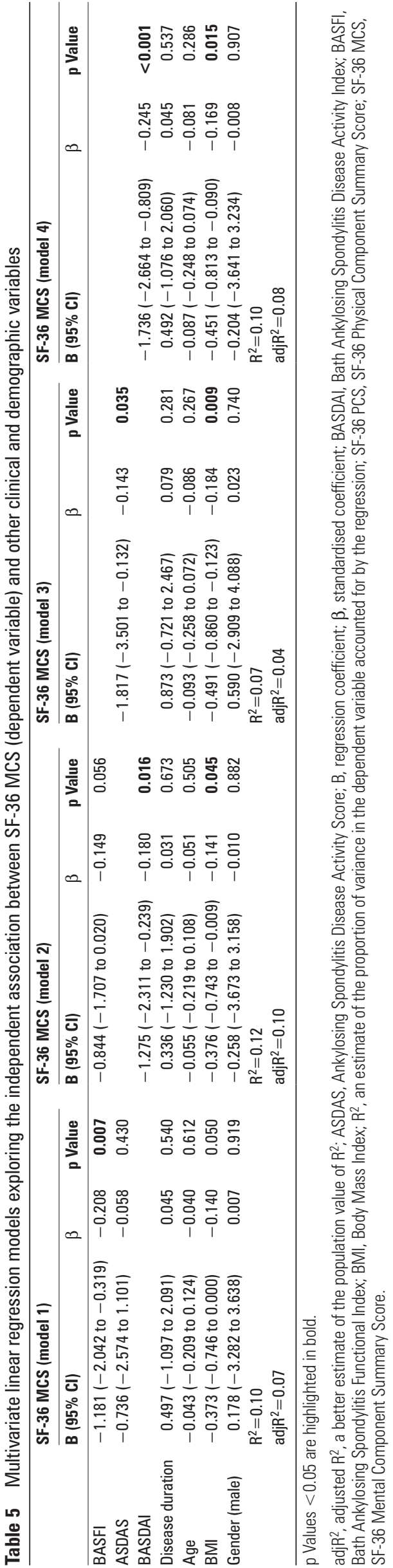




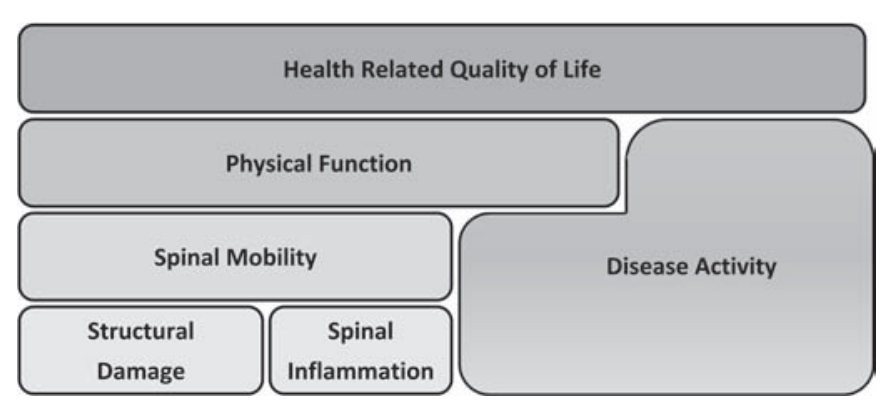

Figure 1 Stratified model for health outcomes in ankylosing spondilytis. The evidence that spinal mobility impairment in ankylosing spondilytis is independently determined both by structural damage and by spinal inflammation is derived from Machado et al. ${ }^{24}$

were associated with SF-36 MCS to a greater extent than ASDAS. However, SF-36 MCS was still independently determined by ASDAS when BASFI was deleted as regressor. Erythrocyte sedimentation rate was not tested because it was not available in ASSERT, and CRP was not included in the multivariate models because its $p$ value was $>0.1$ in univariate analysis.

We have estimated the numerical contribution of each variable over the other. This helps to interpret the results of the regression models by giving them a practical meaning. However, we acknowledge that this is a simplification of reality and that the relations we have investigated may not be truly linear but rather curvilinear, as previously suggested by the correlation between damage and mobility which seems to increase with the level of damage. ${ }^{25}$

The results from this study are consistent with a previous report ${ }^{26}$ showing that physical function in AS is determined by the level of patient-reported disease activity and by the level of radiographic structural damage, in one of the few longitudinal studies addressing health outcomes in AS, with 188 patients included in multivariate analysis. Another longitudinal study ${ }^{27}$ looked at 5-year predictors of disability in 212 patients and found that higher age, smoking, less frequent back exercise and worse social support were associated with a poorer functional outcome. However, this study did not adjust for other variables potentially associated with function such as structural damage, spinal mobility and disease activity.

At the cross-sectional level, Wanders et af ${ }^{25}$ showed acceptable correlations between measures of spinal mobility and measures of structural damage; we have previously shown an independent association between spinal mobility, spinal damage and MRI inflammation of the spine ${ }^{24}$; and Almodovar et af8 described associations between functional capacity and spinal mobility measures. Vesovic-Potic et a ${ }^{29}$ reported a negative independent association between the physical functioning domain of SF-36 and BASFI, while Ozdemir ${ }^{30}$ showed that all SF-36 domains (except for general health) had significant negative correlations with BASDAI and BASFI scores. However, Turan et a ${ }^{\beta 1}$ only found a significant negative correlation between the general health domain and BASDAI, and between the role-emotional domain and BASFI.

A limitation of our study is its cross-sectional design. Another limitation is that it is a clinical trial cohort involving patients with severe and active disease. It would be of interest to validate this model in patients with earlier and less severe disease status. However, we analysed a large cohort of patients $(n=214)$ and explored a large number of outcome measures (from MRI inflammation to HRQoL), adjusting for a number of possible contributing and confounding factors. Such a broad and detailed analysis has never been reported to date. Furthermore, the items used for analysis are generally used in daily clinics and clinical studies. We believe that the associations described here are relevant for the management of patients with AS and may serve as the background model for future longitudinal studies where temporal relationships may be tested. An association does not necessarily imply causation, and only longitudinal studies can evaluate if a change in an outcome measure translates into a subsequent change in the associated measure.

In summary, we have studied in detail the relationships between several AS outcome measures and propose a stratified model for health outcomes in AS. According to this model (figure 1), HRQoL is determined by physical function and disease activity, physical function is determined by spinal mobility and disease activity, and spinal mobility is determined by structural damage and inflammation of the spine. This model explains a large percentage of the variation in the dependent variables, but not the entire variation, suggesting that other variables such as psychological, social, cultural, ethnic and educational factors should also be taken into account in future studies. However, the relationships that we describe are indisputable, are consistent with the conceptual 'continuum of outcome measures' proposed by Tennant and McKenna ${ }^{12}$ and suggest that, in order to optimise HRQoL, both physical function and disease activity should be considered major goals in the treatment of AS. They also suggest that optimal physical function-preserving therapy should focus on improving disease activity and also on maintaining spinal mobility which, on its own, requires both the elimination of spinal inflammation and the prevention of structural damage. This stratified model explains why optimal treatment of AS should be multimodal, involving non-steroidal anti-inflammatory drugs (NSAIDs) and antitumour necrosis factor (anti-TNF) therapy (drugs that have been shown to improve patient-reported disease activity while, for MRI inflammation of the spine, the effect is only clear for anti-TNF) as well as therapies more specifically addressing spinal mobility (such as physical therapy) and progression of structural damage (such as NSAIDs which have shown to inhibit structural progression independently of inflammation). ${ }^{32}$

As we learn more about how to measure AS, our knowledge about the disease improves and we can make better decisions on how to assess and treat it. The model we propose is useful both for the design and interpretation of clinical trials and also for daily clinical practice, and may contribute to guide best practice in the assessment and treatment of patients with AS.

Funding PM was supported by the Fundação para a Ciência e a Tecnologia (FCT) grant SFRH/BD/62329/2009.

Competing interests None.

Ethics approval Ethics approval was obtained for the ASSERT trial, the database used in our analysis.

Provenance and peer review Not commissioned; externally peer reviewed.

\section{REFERENCES}

1. Ward MM. Outcomes in ankylosing spondylitis: what makes the assessment of treatment effects in ankylosing spondylitis different? Ann Rheum Dis 2006;65(Suppl 3):iii25-8.

2. van der Heijde D, Calin A, Dougados M, et al. Selection of instruments in the core set for DC-ART, SMARD, physical therapy, and clinical record keeping in ankylosing spondylitis. Progress report of the ASAS Working Group. Assessments in Ankylosing Spondylitis. J Rheumatol 1999;26:951-4.

3. Zochling J, Sieper J, van der Heijde D, et al. Development of a core set of domains for data collection in cohorts of patients with ankylosing spondylitis receiving anti-tumor necrosis factor-alpha therapy. J Rheumatol 2008;35:1079-82. 
4. Sieper J, Rudwaleit M, Baraliakos X, et al. The Assessment of Spondyloarthritis International Society (ASAS) handbook: a guide to assess spondyloarthritis. Ann Rheum Dis 2009;68(Suppl 2):ii1-44.

5. Creemers MC, Franssen MJ, van't Hof MA, et al. Assessment of outcome in ankylosing spondylitis: an extended radiographic scoring system. Ann Rheum Dis 2005;64:127-9.

6. Wanders AJ, Landewé RB, Spoorenberg A, et al. What is the most appropriate radiologic scoring method for ankylosing spondylitis? A comparison of the available methods based on the Outcome Measures in Rheumatology Clinical Trials filter. Arthritis Rheum 2004;50:2622-32.

7. Braun J, Baraliakos X, Golder W, et al. Magnetic resonance imaging examinations of the spine in patients with ankylosing spondylitis, before and after successful therapy with infliximab: evaluation of a new scoring system. Arthritis Rheum 2003:48:1126-36.

8. Lukas C, Braun J, van der Heijde D, et al. Scoring inflammatory activity of the spine by magnetic resonance imaging in ankylosing spondylitis: a multireader experiment. $J$ Rheumatol 2007;34:862-70.

9. Lukas C, Landewé R, Sieper J, et al. Development of an ASAS-endorsed disease activity score (ASDAS) in patients with ankylosing spondylitis. Ann Rheum Dis 2009;68:18-24.

10. van der Heijde D, Lie E, Kvien TK, et al. ASDAS, a highly discriminatory ASAS-endorsed disease activity score in patients with ankylosing spondylitis. Ann Rheum Dis 2009;68:1811-18.

11. Machado P, Landewé R, Lie E, et al. Ankylosing Spondylitis Disease Activity Score (ASDAS): defining cut-off values for disease activity states and improvement scores. Ann Rheum Dis 2011;70:47-53.

12. Tennant A, McKenna SP. Conceptualizing and defining outcome. Br J Rheumatol 1995;34:899-900.

13. Fries JF. Toward an understanding of patient outcome measurement. Arthritis Rheum 1983;26:697-704.

14. van der Heijde D, Dijkmans B, Geusens $P$, et al. Efficacy and safety of infliximab in patients with ankylosing spondylitis: results of a randomized, placebo-controlled trial (ASSERT). Arthritis Rheum 2005;52:582-91.

15. van der Linden S, Valkenburg HA, Cats A. Evaluation of diagnostic criteria for ankylosing spondylitis. A proposal for modification of the New York criteria. Arthritis Rheum 1984;27:361-8.

16. Ware JE, Jr, Sherbourne CD. The MOS 36-item short-form health survey (SF-36). I. Conceptual framework and item selection. Med Care 1992;30:473-83.

17. Calin A, Garrett S, Whitelock H, et al. A new approach to defining functional ability in ankylosing spondylitis: the development of the Bath Ankylosing Spondylitis Functional Index. J Rheumato/ 1994;21:2281-5.
18. Garrett S, Jenkinson T, Kennedy LG, et al. A new approach to defining disease status in ankylosing spondylitis: the Bath Ankylosing Spondylitis Disease Activity Index. J Rheumatol 1994;21:2286-91.

19. Jones SD, Porter J, Garrett SL, et al. A new scoring system for the Bath Ankylosing Spondylitis Metrology Index (BASMI). J Rheumatol 1995:22:1609.

20. Jenkinson TR, Mallorie PA, Whitelock HC, et al. Defining spinal mobility in ankylosing spondylitis (AS). The Bath AS Metrology Index. J Rheumatol 1994;21:1694-8.

21. van der Heijde D, Landewé R, Feldtkeller E. Proposal of a linear definition of the Bath Ankylosing Spondylitis Metrology Index (BASMI) and comparison with the 2-step and 10-step definitions. Ann Rheum Dis 2008;67:489-93.

22. van Tubergen AM, Landewé RB. Tools for monitoring spondyloarthritis in clinical practice. Nat Rev Rheumatol 2009;5:608-15.

23. Ware JE, Jr, Gandek B, Kosinski M, et al. The equivalence of SF-36 summary health scores estimated using standard and country-specific algorithms in 10 countries: results from the I0OLA Project. International Quality of Life Assessment. J Clin Epidemiol 1998;51:1167-70.

24. Machado P, Landewé R, Braun J, et al. Both structural damage and inflammation of the spine contribute to impairment of spinal mobility in patients with ankylosing spondylitis. Ann Rheum Dis 2010;69:1465-70.

25. Wanders A, Landewé $\mathrm{R}$, Dougados $\mathrm{M}$, et al. Association between radiographic damage of the spine and spinal mobility for individual patients with ankylosing spondylitis: can assessment of spinal mobility be a proxy for radiographic evaluation? Ann Rheum Dis 2005;64:988-94.

26. Landewé R, Dougados M, Mielants $\mathrm{H}$, et al. Physical function in ankylosing spondylitis is independently determined by both disease activity and radiographic damage of the spine. Ann Rheum Dis 2009;68:863-7.

27. Ward MM. Predictors of the progression of functional disability in patients with ankylosing spondylitis. J Rheumato/ 2002;29:1420-5.

28. Almodóvar R, Zarco P, Collantes E, et al. Relationship between spinal mobility and disease activity, function, quality of life and radiology. A cross-sectional Spanish registry of spondyloarthropathies (REGISPONSER). Clin Exp Rheumatol 2009;27:439-45.

29. Vesovic-Potic V, Mustur D, Stanisavljevic D, et al. Relationship between spinal mobility measures and quality of life in patients with ankylosing spondylitis. Rheumatol Int 2009;29:879-84.

30. Ozdemir $\mathbf{0}$. Quality of life in patients with ankylosing spondylitis: relationships with spinal mobility, disease activity and functional status. Rheumatol Int 2011;31:605-10.

31. Turan Y, Duruöz MT, Cerrahoglu L. Quality of life in patients with ankylosing spondylitis: a pilot study. Rheumatol Int 2007;27:895-9.

32. Wanders A, Heijde D, Landewé R, et al. Nonsteroidal antiinflammatory drugs reduce radiographic progression in patients with ankylosing spondylitis: a randomized clinical trial. Arthritis Rheum 2005:52:1756-65. 


\section{ARD}

\section{A stratified model for health outcomes in ankylosing spondylitis}

Pedro Machado, Robert Landewé, Jürgen Braun, et al.

Ann Rheum Dis published online July 25, 2011

doi: 10.1136/ard.2011.150037

Updated information and services can be found at:

http://ard.bmj.com/content/early/2011/07/25/ard.2011.150037.full.html

\section{These include:}

Data Supplement

References

$\mathbf{P}<\mathbf{P}$

Email alerting service
"Web Only Data"

http://ard.bmj.com/content/suppl/2011/06/24/ard.2011.150037.DC1.html

This article cites 31 articles, 14 of which can be accessed free at: http://ard.bmj.com/content/early/2011/07/25/ard.2011.150037.full.html\#ref-list-1

Published online July 25, 2011 in advance of the print journal.

Receive free email alerts when new articles cite this article. Sign up in the box at the top right corner of the online article.

Advance online articles have been peer reviewed and accepted for publication but have not yet appeared in the paper journal (edited, typeset versions may be posted when available prior to final publication). Advance online articles are citable and establish publication priority; they are indexed by PubMed from initial publication. Citations to Advance online articles must include the digital object identifier (DOIs) and date of initial publication.

To request permissions go to:

http://group.bmj.com/group/rights-licensing/permissions

To order reprints go to:

http://journals.bmj.com/cgi/reprintform

To subscribe to BMJ go to:

http://group.bmj.com/subscribe/ 
Topic Articles on similar topics can be found in the following collections Collections

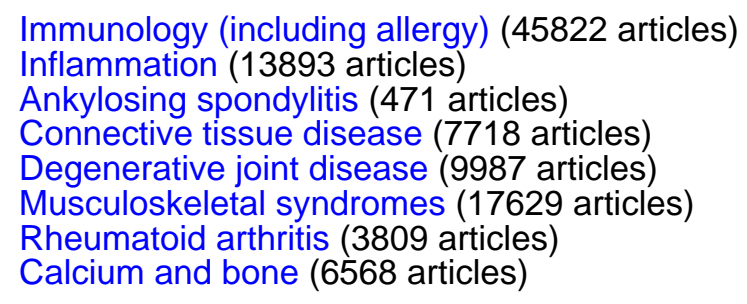

\section{Notes}

Advance online articles have been peer reviewed and accepted for publication but have not yet appeared in the paper journal (edited, typeset versions may be posted when available prior to final publication). Advance online articles are citable and establish publication priority; they are indexed by PubMed from initial publication. Citations to Advance online articles must include the digital object identifier (DOIs) and date of initial publication.

To request permissions go to:

http://group.bmj.com/group/rights-licensing/permissions

To order reprints go to:

http://journals.bmj.com/cgi/reprintform

To subscribe to BMJ go to:

http://group.bmj.com/subscribe/ 